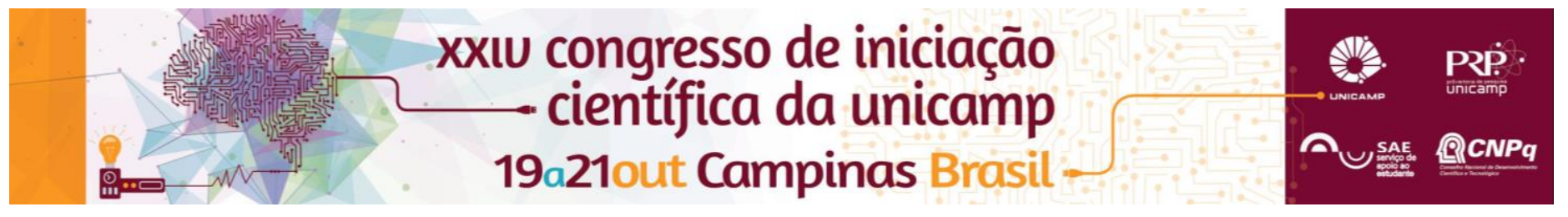

\title{
Estudos Determinísticos de Soluções para os Impactos Técnicos resultantes da Conexão Massiva de Veículos Elétricos aos Sistemas de Distribuição
}

\section{Lucas de A. Ramirez*, Fernanda C. T. Arioli.}

\section{Resumo}

Recentemente, os veículos elétricos surgiram como uma tecnologia de apelo sustentável significativo, impactando diretamente na redução da emissão do dióxido de carbono $\left(\mathrm{CO}_{2}\right)$ em grandes centros urbanos. No entanto, por se tratar de uma tecnologia nova, que deve ser conectada aos sistemas de distribuição de energia elétrica para recarga e que representa elevado consumo de potência, necessita-se de estudos que apontem qual deve ser o foco de preocupação das concessionárias de energia elétrica e quais soluções devem ser adotadas. Os resultados destes estudos podem auxiliar as concessionárias na tomada de decisão sobre quais soluções técnicas adotar e, consequentemente, resultar na maior disseminação desta tecnologia.

\section{Palavras-chave}

Impactos Técnicos, Recarga de Veículos Elétricos, Sistemas de Distribuição de Energia Elétrica

\section{Introdução}

O uso de veículos elétricos (VE) como alternativa aos tradicionais veículos de motores a combustão interna representa um benefício para o meio ambiente. Quando recarregados em redes elétricas com menor dependência de energia provinda de fontes poluentes, as emissões de $\mathrm{CO}_{2}$ podem ser reduzidas de $50 \%$ a $60 \%{ }^{1}$. A Organização das Nações Unidas desenvolveu a iniciativa de mobilidade elétrica urbana com o objetivo de aumentar a adoção de VEs em cidades e com a meta de que até o ano de 2030, as viagens realizadas em VEs representem até $30 \%$ das viagens urbanas ${ }^{2}$. Diante deste contexto de incentivo à adoção de VEs, as concessionárias de energia elétrica precisam estar aptas a lidar com a iminente conexão massiva de VEs, para atender esta demanda sem comprometer a qualidade do fornecimento de energia elétrica.

Os veículos do tipo Plug-In Electric Vehicles (PEV) possuem baterias de alta capacidade e são recarregados através da conexão à rede elétrica através de infraestrutura de recarga. Os PEVs são o foco deste trabalho, que objetiva o estudo de soluções para os impactos causados pela conexão de VEs à rede de distribuição. Durante a recarga residencial, os PEVs podem consumir $3,5 \mathrm{~kW}$ por 8 horas. O efeito cumulativo de vários PEVs conectados às redes de baixa tensão são fator de preocupação das concessionárias.

\section{Resultados e Discussão}

Os resultados deste trabalho ainda são preliminares. Basicamente, realizaram-se estudos dos impactos técnicos para que, em seguida, as soluções possam ser avaliadas. Entre os impactos mais significativos na rede elétrica de baixa tensão devido a conexão massiva de VE estão a queda de tensão, que pode resultar na violação dos valores regulamentados pela $\mathrm{ANEEL}^{3}$ e sobrecarga. Os níveis de tensão para redes com tensão nominal inferior a $1 \mathrm{kV}$ tem limite inferior de $0,92 \mathrm{pu}$.

Simulações de fluxo de potência série temporal foram realizadas em uma rede de baixa tensão residencial típica brasileira, utilizando o software OpenDSS ${ }^{4}$. A Figura 1 mostra o perfil da tensão mínima do sistema e o carregamento do transformador ao longo de um dia com e sem PEVs conectados à rede.

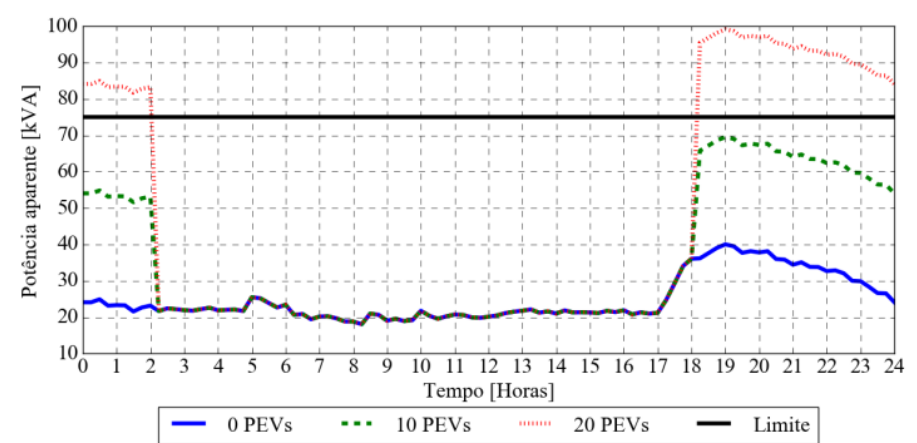

(a) Potência entregue pelo transformador de distribuição

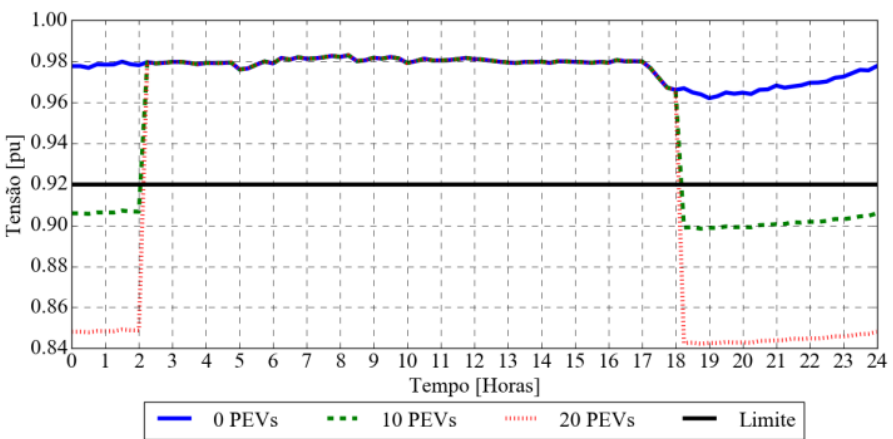

(b) Tensão mínima na rede de baixa tensão

Figura 1. Impactos na rede devido a conexão de múltiplos PEVs.

\section{Conclusões}

Este trabalho apresenta resultados preliminares relacionados à identificação dos impactos técnicos da recarga de PEVs que serão usados para a avaliação de soluções como: recarga inteligente, recondutoramento, ou o uso de reguladores de tensão.

\section{Agradecimentos}

Este trabalho foi financiado pela FAEPEX (Fundo de Apoio ao Ensino, à Pesquisa e Extensão).

\footnotetext{
${ }^{1}$ Huo, H.; Cai, H.; Zhang, Q.; Liu, F. e He, K. Life-cycle assessment of greenhouse gas and air emissions of electric vehicles: A comparison between China and the U.S.. Atmospheric Environment. 2015, 108, 107-116.

${ }^{2}$ United Nations. Climate Summit: Urban Electric Mobility Initiative. [Online] $<$ http://goo.gl/o3GbDg> (Acessado em Maio 05, 2016).

${ }^{3}$ Procedimentos de distribuição de energia elétrica no sistema elétrico nacional (PRODIST); Módulo 8 Qualidade da energia elétrica. pp 1-75 2015.

${ }^{4}$ OpenDSS $<$ https://sourceforge.net/projects/electricdss/>
} 